Disclosure of Interests: None declared

DOI: 10.1136/annrheumdis-2021-eular.2144

\begin{tabular}{|l|l}
\hline POS1353 & SERUM PROTEOMICS REVEALS INSULIN-LIKE \\
GROWTH FACTOR BINDING PROTEINS-1 AS \\
BIOMARKERS FOR IDIOPATHIC MULTICENTRIC \\
CASTLEMAN'S DISEASE
\end{tabular}

R. Sumiyoshi', T. Koga ${ }^{1}$, A. Kawakami ${ }^{1}{ }^{1}$ Nagasaki University Graduate School of Biomedical Sciences, Department of Immunology and Rheumatology, Division of Advanced Preventive Medical Sciences, Nagasaki, Japan

Background: Castleman's disease (CD) is a lymphoproliferative disorder ${ }^{1}$ and presents as two distinct clinical entities: the localized form, unicentric CD (UCD) and the multicentric form, multicentric $C D(M C D)^{2}$. $M C D$ without human herpesvirus-8 (HHV-8) infection is defined idiopathic MCD (iMCD) ${ }^{3}$ and most MCDs in Japan are iMCDs. TAFRO syndrome is a group of disease that present with $\mathrm{T}$ : thrombocytopenia, A: anasarca, F: fever, R: reticulin fibrosis/renal dysfunction, $O$ : organomegaly ${ }^{4}$. iMCD-TAFRO is present in the TAFRO syndrome and it is thought that pathology of lymph node biopsy shows an MCD-like appearance, and some clinical features overlap with $\mathrm{MCD}^{5}$. That do not belong to any of the above categories is classified as iMCD-not otherwise specified (iMCD-NOS). No biomarkers stratifying iMCD-NOS and IMCD-TAFRO have been identified, and no biomarkers defining treatment response have been identified for iMCD.

Objectives: We will identify biomarkers that discriminate iMCD-NOS and iMCD-TAFRO or predict the treatment responsiveness.

Methods: We performed a comprehensive analysis of serum proteins using the L-Series Human Antibody Array L-507 on the 4 iMCD-NOS and 2 iMCD-TAFRO patients from which pre- and post-tocilizumab treatment samples were obtained. An analysis by L-507 identified insulin-like growth factor binding proteins-1 (IGFBP-1) as a protein with a high rate of reduction post treatment. Sera from 28 healthy controls, 8 patients with iMCD-NOS, and 6 patients with iMCD-TAFRO were used to validate IGFBP-1 by ELISA. The mean ages of healthy controls, iMCD-NOS, and IMCD-TAFRO used in the validation ELISA were 50, 56, and 47 years, respectively, with no significant differences among the groups. The ratio of male to female was almost 1:1.

Results: The 4 patients who responded well to treatment with tocilizumab all had a high rate of IGFBP-1 reduction by L-507 serum protein arrays. In ELISA, serum IGFBP-1 was significantly higher $(p=0.0016)$ before the introduction of treatment in iMCD patients than healthy controls. In addition, serum IGFBP-1 level of iMCD-TAFRO was significantly higher than iMCD-NOS $(p=0.024)$. Furthermore, post-treatment serum IGFBP-1 was decreased in many cases.

Conclusion: Serum IGFBP-1 may play a particularly important role in the pathogenesis of iMCD-TAFRO and may be useful in discriminating between IMCDNOS and iMCD-TAFRO. In the future, we will accumulate more cases, compare it with other inflammatory diseases, and examine the difference in response to treatment.

REFERENCES:

[1] CASTLEMAN, et al. 1954. CASE records of the Massachusetts General Hospital Weekly Clinicopathological Exercises: Case 40011. N Engl J Med, 250, 26-30.

[2] WATERSTON, et al. 2004. Fifty years of multicentric Castleman's disease. Acta Oncol, 43, 698-704.

[3] FAJGENBAUM D, et al. 2014. HHV-8-negative, idiopathic multicentric castleman disease (iMCD): A description of clinical features and therapeutic options through a systematic literature review. Blood (ASH Annual Meeting Abstracts), 124, 4861.

[5] TAKAI K, et al. 2010. Thrombocytopenia with mild bone marrow fibrosis accompanied by fever, pleural effusion, ascites and hepatosplenomegaly [in Japanese]. Rinsho Ketsueki, 51, 320-325.

[6] IWAKI N, et al. 2016. Clinicopathologic analysis of TAFRO syndrome demonstrates a distinct subtype of HHV-8-negative multicentric Castleman disease. Am J Hematol, 91, 220-226.

Disclosure of Interests: None declared

DOI: 10.1136/annrheumdis-2021-eular.2246

\section{POS1354 \\ GENDER DIFFERENCES IN CLINICAL FEATURES AND BURDEN IN PATIENTS WITH FAMILIAL MEDITERRANEAN FEVER: PRELIMINARY REPORT}

M. T. Duruöz ${ }^{1}$, A. Ozer ${ }^{1}$, H. H. Gezer ${ }^{1}$, M. Alkan Melikoglu' ${ }^{2}$, S. Hizmetli ${ }^{3}$, H. S. Baklacioglu ${ }^{4}$, N. Sahin ${ }^{5}$, N. Öz $z^{1}$, D. Erdem Gürsoy ${ }^{6}$, D. Altıntaş ${ }^{7}$, P. Oba ${ }^{8}$, S. Acer Kasman ${ }^{1} .{ }^{1}$ Marmara University School of Medicine, PMR Department, Rheumatology Division, Istanbul, Turkey; ${ }^{2}$ Ataturk University School of Medicine, PMR Department, Rheumatology Division, Erzurum, Turkey; ${ }^{3}$ Cumhuriyet University School of Medicine, PMR Department, Rheumatology Division, Sivas, Turkey; ${ }^{4}$ Samsun Training and Research Hospital, Rheumatology Clinic, Samsun, Turkey; ${ }^{5}$ Balikesir University School of Medicine, PMR Department,
Ballkesir, Turkey; ${ }^{6}$ Adlyaman Training and Research Hospital, Rheumatology Clinic, Adıvaman, Turkey; ${ }^{7}$ Ataturk University School of Medicine, PMR Department, Erzurum, Turkey; ${ }^{8}$ Cumhuriyet University School of Medicine, PMR Department, Sivas, Turkey

Background: Familial Mediterranean fever (FMF) is the most common hereditary auto-inflammatory disease, which is more common in groups in the Mediterranean basin, characterized by recurrent attacks of febrile peritonitis, pleuritis and arthritis.

Objectives: The aim of this study is to investigate the gender differences in clinical and demographic features in patients with familial Mediterranean fever (FMF). Methods: Patients with FMF diagnosed according to Tel-Hashomer criteria were included in this multi-center study. Data about age, sex, disease duration, symptom duration, age at diagnosis, comorbid diseases and medications were noted. All patients were screen with Hospital Anxiety and Depression Scale (HADS) Health Assessment Questionnaires (HAQ), Short Form 36 (SF-36). The severity of FMF was assessed by the PRASS scoring system.

Results: Of the 286 patients, $199(69,6 \%)$ were female with the mean age $36,2($ SD: 12.32$)$ years and 87 (30,4\%) were male with the mean age 32,9 (SD:12,6) years $(p=0,017)$. Age of diagnosis in male patients was lower than in females $(p=0,008)$. The most common genetic mutation in both genders was M694V gene mutation. Homozygous M694V positivity was higher in males $(31,79 \%$ vs $17,4 \%)$. More than $90 \%$ of patients were receiving colchicine, $10(3,5 \%)$ patients were receiving anakinra and $5(1,75 \%)$ patients were receiving canakinumab. Among the patients regularly taking colchicine, $86.2 \%$ were females and $86 \%$ were males $(p=0,981)$. There were no differences between male and females in terms of clinical findings, frequency and duration of attacks, presence of colchicine resistance, and the presence of amyloidosis $(p>0.05)$. ESR was detected higher in female group $(p=0,011)$. Headache $(p=0,001)$, migraine $(p=0,031)$, and concomitant diseases $(p=0,017)$ were also more common in females than males. Anxiety and depression scores were higher in females $(p<0,05)$. The PRASS activity scores were similar between genders $(p>0,05)$. All parameters of SF-36 were higher in male patients, while HAQ score was higher in females $(p<0,05)$. Conclusion: Although clinical findings, disease severity and treatment compliance are similar in both genders, males are diagnosed with FMF earlier than females, but findings such as anxiety, depression, migraine, and headache are more common in female patients.

\section{REFERENCES:}

[1] Doğan HO, Koca Y, Erden G, Karaaslan Y, Bozat H. Evaluating MEFV mutation frequency in Turkish familial Mediterranean fever suspected patients and gender correlation: a retrospective study. Mol Biol Rep. 2012 May;39(5):6193-6.

Table 1. Demographic and clinical features between female and male FMF patients.

\begin{tabular}{|c|c|c|c|}
\hline & Female (n:199) & Male (n:87) & $P$ \\
\hline \multicolumn{4}{|l|}{ Demographic features, mean (SD) } \\
\hline Age & $36,2(12.32)$ & $32,9(12,6)$ & 0,017 \\
\hline BMI & $26,87(5,73)$ & $25,79(5,28)$ & 0,177 \\
\hline Educational level, years & $8,77(4,36)$ & $12,08(3,23)$ & 0,000 \\
\hline Age at diagnosis & $28(13,31)$ & $23,7(13,42)$ & 0,008 \\
\hline Age at onset of disease & $19,2(12,6)$ & $17(10,6)$ & 0,265 \\
\hline \multicolumn{4}{|l|}{ Clinical features, $\mathrm{n}(\%)$} \\
\hline Fever & $166(83,4)$ & $77(88,5)$ & 0,268 \\
\hline Abdominal pain & $180(90,5)$ & $78(89,7)$ & 0,835 \\
\hline Chest pain & $62(31,2)$ & $20(23)$ & 0,160 \\
\hline Erysipelas like erythema & $12(6)$ & $4(4)$ & 0,628 \\
\hline Arthritis & $46(23,1)$ & $24(24)$ & 0,419 \\
\hline Arthralgia & $102(51,3)$ & $42(48,3)$ & 0,643 \\
\hline Myalgia & $101(50,8)$ & $47(54)$ & 0,611 \\
\hline \multicolumn{4}{|l|}{ MEVF mutations, $\mathbf{n}(\%)$} \\
\hline M694V/M694V & $24(12.3)$ & $19(22)$ & 0.047 \\
\hline M694V heterozygous & $38(19,5)$ & $14(16,3)$ & 0.523 \\
\hline M694V/any & $25(12,8)$ & $15(17,4)$ & 0.307 \\
\hline PRASS disease severity, n (\%) & & & 0,813 \\
\hline Mild & $99(49,7)$ & $46(52,9)$ & \\
\hline Moderate & $88(44,2)$ & $35(40,2)$ & \\
\hline Severe & $12(6)$ & $6(6,9)$ & \\
\hline ESR, mm/hour, mean (SD) & $23,77(16,27)$ & $18,25(18,41)$ & 0,011 \\
\hline $\mathrm{HAQ}$, mean (SD) & $0,49(0,63)$ & $0,16(0,43)$ & 0,000 \\
\hline \multicolumn{4}{|l|}{ HAD, mean (SD) } \\
\hline Anxiety & $8,4(4,4)$ & $6,7(3,44)$ & 0,003 \\
\hline Depression & $7,1(4,27)$ & $5,7(3,81)$ & 0,006 \\
\hline \multicolumn{4}{|l|}{ SF-36, mean (SD) } \\
\hline Physical functioning & $63,56(23,81)$ & $79,93(19,32)$ & 0,000 \\
\hline Physical role limitation & $45,78(40,95)$ & $61,41(39,14)$ & 0,003 \\
\hline Emotional role limitation & $47,36(42,04)$ & $66,20(40,69)$ & 0,020 \\
\hline Energy/fatigue & $42,50(20,64)$ & $53,64(19,82)$ & 0,000 \\
\hline Emotional well-being & $51,61(18,47)$ & $58,74(18,30)$ & 0,003 \\
\hline Social functioning & $57,06(23,09)$ & $70,52(23,82)$ & 0,000 \\
\hline Pain & $51,66(24,05)$ & $65,72(24,51)$ & 0,000 \\
\hline General health & $39,53(20,01)$ & $52,46(23,83)$ & 0,000 \\
\hline
\end{tabular}


Disclosure of Interests: None declared

DOI: 10.1136/annrheumdis-2021-eular.2317

\section{POS1355 SYNOVITIS WITH PITTING EDEMA SYNDROME (RS3PE): REVIEW OF TEN YEARS AT A REFERENCE HOSPITAL}

S. Garcia Perez ${ }^{1}$, J. L. Modesto Dos Santos ${ }^{2}$, J. Mendizabal ${ }^{1}$, M. López I Gómez ${ }^{1}$, G. Sada ${ }^{1}$, J. Restrepo Vélez ${ }^{1}$, J. I. Elejalde ${ }^{2}$, L. Garrido Courel $^{1}$, V. Aldasoro ${ }^{1}$, I. Paniagua Zudaire ${ }^{1}$, R. Gutierrez ${ }^{1}$, L. Horcada ${ }^{1}$, F. J. Anniccherico ${ }^{2}$, N. Del Val del Amo ${ }^{1}$, M. C. Fito Manteca ${ }^{1}$, J. Sanchez Alvarez ${ }^{2}$ ${ }^{1}$ Complejo Hospitalario de Navarra (CHN), Rheumatology, Pamplona, Spain; ${ }^{2}$ Complejo Hospitalario de Navarra (CHN), Internal Medicine, Pamplona, Spain

Background: The Remitting Seronegative Symmetrical Synovitis with Pitting Edema Syndrome (RS3PE) is a rare rheumatological disease, considered a benign process.

Objectives: This study aims to describe its clinical features and serological markers, and also to analyze its possible association with neoplasms.

Methods: An observational retrospective study was performed to assess demographic and clinical characteristics of patients diagnosed from RS3PE at a reference hospital amongst the Rheumatology and Internal Medicine departments, from 2010 to 2021.

Results: Twenty-seven patients were included, with a mean age of 82.74 y.o. (IC95\% 80.45-85.04; range 66 to 93), and a $51.85 \%$ proportion of males. Only $22.22 \%$ were from rural areas.

All patients presented bilateral hand edema although some associated feet edema $(40.74 \%)$ or morning stiffness $(70.37 \%)$. Blood tests demonstrated anemia in $44.44 \%$ of patients. Inflammatory markers were elevated, such as C-Reactive Protein (29.23 mg/L, IC95\% 18.17-40.29), erythrocyte-sedimentation rate $(33.74 \mathrm{~mm} /$ hour, IC95\% $24.22-43.26)$ and fibrinogen $(531.6 \mathrm{mg} / \mathrm{dL}$, IC95\% 482.91-580.30). Only a few patients presented any autoimmune serological marker such as antinuclear antibodies $(18.18 \%)$ or rheumatoid factor $(8.70 \%)$ $\mathrm{X}$-ray screening was realized to 22 patients. 14 showed of osteoarthritis radiologic presentation, 4 had radiological findings of chondrocalcinosis and one of them presented both. Only one patient had bone erosion.

Malignancy screening was performed at diagnosis in only $29.63 \%$ of patients (all negative). During follow-up only two tumors were detected (mean accumulated follow-up: 40.37 months, IC95\% 26.70-54.04; range 1 to 122) and there were adenocarcinoma primary neoplasms.

All but one patient received low-dose corticosteroids, with a good and rapid response in all cases. Three patients received treatment with methotrexate (2) or leflunomide (1).

Conclusion: RS3PE must be contemplated in elderly patients presenting with bilateral hand pitting edema and articular symptoms. No specific biomarkers have been described, but inflammatory reaction is often found in the absence of rheumatoid arthritis biomarkers. Rapid response to corticosteroids is prevalent. Only two neoplasms were detected during follow-up.

REFERENCES:

[1] Paira S, Graf C, Roverano S, Rossini J. Remitting seronegative symmetrical synovitis with pitting oedema: a study of 12 cases. Clin Rheumatol. 2002 May;21(2):146-9. doi: 10.1007/pI00011218. PMID: 12086166.

[2] Cobeta García JC, Martínez Burgui J. RS3PE syndrome or benign edematous polysynovitis in the elderly. Study of 8 cases. Rev Clin Esp. 1999 Dec;199(12):785-9. Spanish. PMID: 10687410.

[3] Moreno Obregón F, Del Castillo Madrigal M, Díaz Narváez F, Pérez Delgado FJ. RS3PE syndrome with positive rheumatoid factor. Reumatol Clin. 2019 Nov-Dec;15(6):e168-e169. English, Spanish. doi: 10.1016/j. reuma.2017.11.009. Epub 2017 Dec 15. PMID: 29254743

Disclosure of Interests: None declared

DOI: 10.1136/annrheumdis-2021-eular.2646

\section{POS1356 \\ PERSISTENCE OF TFH CELLS AFTER RITUXIMAB S ASSOCIATED WITH IGG4-RELATED DISEASE RELAPSE}

G. Mancuso $^{1,2}$, T. Jofra ${ }^{3}$, M. Lanzillotta ${ }^{4}$, J. Gerosa $^{3}$, G. DI Colo ${ }^{2}$, L. Dagna ${ }^{2}$ G. Fousteri ${ }^{3}$, E. Della Torre ${ }^{2}{ }^{1}$ Università Vita-Salute San Raffaele, Allergologia ed Immunologia clinica, Milano, Italy; ${ }^{2}$ Ospedale San Raffaele, Immunologia, Reumatologia, Allergologia e Malattie Rare, Milano, Italy; ${ }^{3}$ Università Vita-Salute San Raffaele, Diabetes Research Institute (DRI), Milano, Italy; ${ }^{4}$ Università VitaSalute San Raffaele, Internal medicine, Milano, Italy

Background: Clinical improvement after B-cell depletion with rituxmab suggests a prominent pathogenic role of B-lymphcytes in IgG4-related disease (IgG4-RD). IgG4-RD, however, relapses in most cases together with re-expansion of clonally divergent plasmablasts indicating that treatment with rituximab does not completely abrogates $\mathrm{T}$ follicular helper (Tfh)-cells dependent germinal center reactions leading to de-novo plasmablast differentiation.

Objectives: In the present work we aim to study the effects of B-cell depletion therapy with rituximab on circulating Tfh cells and on the levels of CXCL13 - a chemotactic factor for B-lymphocytes produced by Tfh cells - in patients with IgG4-RD.

Methods: Thirty patients with IgG4-RD, diagnosed according to the "Consensus Statement on the Pathology of IgG4-RD" and fulfilling the "2019 ACR/EULAR Classification Criteria" were included in the present study. Ten patients with relapsing disease were treated with the anti-CD20 monoclonal antibody rituximab (two $1 \mathrm{~g}$ infuxions 15 days apart). Peripheral blood mononuclear cells and serum were collected before rituximab and three months after infusion. Tfh cells subsets in the peripheral blood were measured by flow cytometry and CXCL13 plasma levels were measured by ELISA assay.

Results: No changes in total Tfh cells and Tfh cells subsets were observed three months after rituximab neither in absolute counts nor in percentage of CD4+ T cells. In particular, no difference in Tfh1, Tfh2, Tfh17, T follicular regulatory and highly functional Tfh cells counts was observed before and after treatment. The serum level of CXCL13 was significantly higher in active untreated IgG4-RD patients compared to healthy controls $(151.94 \mathrm{pg} / \mathrm{ml}$ vs $66.98 \mathrm{pg} / \mathrm{ml}, \mathrm{p}$ value $=$ 0.0026 ), but was not affected by rituximab treatment ( $p$ value $=0.41$ ).

Conclusion: In relapsing patients with IgG4-RD rituximab does not affect circulating Tfh cells numbers and serum levels of CXCL13. Persistence of Tfh cells after rituximab and reconstitution of germinal center reactions likely drives IgG4-RD flare.

\section{REFERENCES:}

[1] Lanzillotta M, Mancuso G, Della-Torre E. Advances in the diagnosis and management of IgG4 related disease. BMJ. 2020 Jun 16;369:m1067. doi: 10.1136/bmj.m1067. PMID: 32546500.

[2] Lanzillotta M, Della-Torre E, Stone JH. Roles of Plasmablasts and B Cells in IgG4-Related Disease: Implications for Therapy and Early Treatment Outcomes. Curr Top Microbiol Immunol. 2017;401:85-92. doi: 10.1007/82_2016 58. PMID: 28091934.

[3] Campochiaro C, Ramirez GA, Bozzolo EP, Lanzillotta M, Berti A, Baldissera E, Dagna L, Praderio L, Scotti R, Tresoldi M, Roveri L, Mariani A, Balzano G, Castoldi R, Doglioni C, Sabbadini MG, Della-Torre E. IgG4-related disease in Italy: clinical features and outcomes of a large cohort of patients. Scand $J$ Rheumatol. 2016;45(2):135-45. doi: 10.3109/03009742.2015.1055796. Epub 2015 Sep 23. PMID: 26398142.

[4] Mattoo H, Mahajan VS, Della-Torre E, Sekigami Y, Carruthers M, Wallace ZS, Deshpande V, Stone JH, Pillai S. De novo oligoclonal expansions of circulating plasmablasts in active and relapsing IgG4-related disease. J Allergy Clin Immunol. 2014 Sep;134(3):679-87. doi: 10.1016/j.jaci.2014.03.034. Epub 2014 May 6. PMID: 24815737; PMCID: PMC4149918.

Disclosure of Interests: None declared

DOI: 10.1136/annrheumdis-2021-eular.2715

\section{\begin{tabular}{|l|l}
\hline POS1357 & OCULAR SCLERAL PATHOLOGY. UNDERLYING \\
\hline
\end{tabular} DISEASES AND SYSTEMIC TREATMENT. STUDY OF 175 PATIENTS FROM A SINGLE UNIVERSITY CENTER}

L. Sanchez-Bilbao ${ }^{1}$, V. Calvo-Río ${ }^{1}$, J. L. Martín-Varillas ${ }^{2}$, C. Álvarez-Reguera ${ }^{1}$, A. Herrero-Morant ${ }^{1}$, I. González-Mazón ${ }^{1}$, R. Demetrio-Pablo ${ }^{3}$, M. A. GonzálezGay ${ }^{1}$, R. Blanco ${ }^{1} .{ }^{1}$ H.U. Marqués de Valdecilla, Rheumatology, Santander, Spain; ${ }^{2}$ H. Sierrallana, Rheumatology, Torrelavega, Spain; ${ }^{3}$ H.U. Marqués de Valdecilla, Ophthalmology, Santander, Spain

Background: Ocular scleral pathology (OSP) includes episcleritis and scleritis Episcleritis is generally a benign disease with a self-limited course, while scleritis is a more severe ocular condition. In some severe and refractory cases systemic therapy may be required.

Objectives: In a wide series with OSP our aim was to assess a) underlying diseases and $\mathbf{b}$ ) systemic treatment.

Methods: Study of unselected all consecutive patients studied in a single University Hospital during the last ten years with: a) episcleritis and b) scleritis diagnosed by clinical features and slit-lamp (Watson and Hayreh criteria). Best corrected visual acuity (BCVA) and intraocular pressure (IOP) were measured at diagnosis and after systemic treatment.

Results: We studied 175 patients (106 women/ 69 men) /212 affected eyes with OSP (episcleritis $=135$; scleritis $=40$ ); mean age $48.9 \pm 14.2$ years .

OSP was unilateral in $138(78.9 \%)$, recurrent in $74(42.9 \%)$ and chronic in 21 $(12 \%)$. Most of them were idiopathic $(n=81,46.3 \%)$ while associated with IMID were $43.4 \%$ (Table 1). The most important underlying IMID were spondyloarthritis and inflammatory bowel disease, without significant differences between scleritis and episcleritis. Granulomatosis with polyangiits and systemic lupus erythematosus were more frequent in scleritis, not reaching statistical significance. Regarding treatment, topical treatment was used in all patients. $41.1 \%$ received systemic treatment, including systemic glucocorticoids, cDMARDS and 